\title{
Entre la buena voluntad y la compulsión hegemónica: las implicaciones políticas del intercambio filológico latinoamericano-alemán
}

\author{
Juan R. Valdez ${ }^{1}$ \\ Mills College, EE. UU. \\ Silke Jansen ${ }^{2}$ \\ Friedrich-Alexander-Universität Erlangen-Nürnberg, Alemania
}

\begin{abstract}
Resumen
El objetivo de este estudio es examinar críticamente la obra filológicaetnográfica de varios investigadores europeos y latinoamericanos que en épocas previas aportaron consciente o inadvertidamente a la exacerbación o resolución de crisis políticas en Latinoamérica. Enfocándonos en el caso guatemalteco, intentamos determinar cuáles filólogos y etnólogos abordaron el asunto de la regulación del idioma y que reflexionaron en torno a las consecuencias políticas de intervenir en la cultura lingüística en determinados contextos regionales. Utilizando métodos del análisis crítico del discurso con un enfoque glotopolítico, contrastamos las representaciones lingüísticas y descripciones etnográficas elaboradas por varios filólogos, mayormente alemanes, que trabajaron en Guatemala con las de Rodolfo Lenz sobre el criollo hablado por un informante
\end{abstract}

\footnotetext{
1 Para correspondencia, dirigirse a: Juan R. Valdez, valdezjuan158@gmail.com, Mills College, 5000 MacArthur Blvd., Oakland, CA 94613, EE.UU.

2 Para correspondencia, dirigirse a: Silke Jansen, silke.jansen@fau.de, FriedrichAlexander-Universität Erlangen-Nürnberg, Bismarckstr. 1, D-91054 Erlangen, Alemania.
} 
curazoleño y la lengua popular en Chile. Intentamos yuxtaponer la filología etnográficamente crítica de Lenz a la práctica filológica institucionalizada. Nuestros resultados demuestran que los grados de compromiso entre los filólogos y los grupos sociales estudiados variaron en función de los grados de compulsión y desapego hegemónico que sintieron dichos filólogos y el valor de una determinada lengua en los diferentes contextos de luchas sociales.

Palabras clave: filología, etnografía, representaciones lingüísticas, Leonhard Schultze-Jena, Guatemala, Rodolfo Lenz.

\author{
BETWEEN GOODWILL AND HEGEMONIC COMPULSION: \\ THE POLITICAL IMPLiCATIONS OF THE LATIN AMERICAN-GERMAN \\ PHILOLOGICAL EXCHANGE
}

\begin{abstract}
The objective of this study is to critically examine the philologicalethnographic work of several European and Latin American researchers who previously contributed consciously or inadvertently to the exacerbation or resolution of political crises in LatinAmerica. Focusing on the Guatemalan case, we try to determine which philologist and ethnologists addressed the issue of language regulation and reflected on the political consequences of intervening in the linguistic cultures of certain regions. Utilizing methods of critical discourse analysis with a glottopolitical focus, we contrast the linguistic representations and ethnographic descriptions elaborated by several, mostly German, philologists who worked in Guatemala with those of Rodolfo Lenz regarding the creole spoken by an informant from Curaçao and popular speech in Chile. We try to juxtapose Lenz's ethnographically critical philology with the institutionalized philological practices. Our results show that the degrees of commitment between philologists and the social groups they studied varied depending on the degrees of hegemonic compulsion and detachment felt by these philologists and the value of a given language in the different contexts of social struggles.
\end{abstract}

Keywords: philology, ethnography, linguistic representation, Leonhard Schultze-Jena, Guatemala, Rodolfo Lenz.

Recibido: 24/04/19

Aceptado: 23/09/19 


\section{INTRODUCCIÓN}

En este estudio abordamos la labor filológica-lingüística llevada a cabo por varios investigadores europeos, mayormente alemanes, en contextos de explotación colonial o contextos neocoloniales en Latinoamérica: en Guatemala y en Curazao y Chile, respectivamente. En concreto, analizamos comparativamente los textos filológicos de Otto Stoll, Karl Sapper, Leonhard Schultze-Jena y Franz Termer en Guatemala y, como máximo punto de contraste, los de Rodolfo Lenz sobre el papiamento de Curazao y el español popular en Chile. Nos interesa, la relación de estos filólogos con el entorno local, el aparato estatal, el discurso colonial y, especialmente, las implicaciones, políticas, económicas, étnicas y, hasta, afectivas que emergen en sus descripciones y reflexiones en varios textos importantes. Con este esfuerzo, intentamos dialogar con los estudiosos que se preocupan de las fuentes discursivas y ramificaciones socioculturales de ciertas inquietudes por la lengua en momentos de aguda crisis política e integrar este tipo de estudios interdisciplinariamente ${ }^{3}$. Si bien dialogamos con varias disciplinas que destacan el estudio contextual del lenguaje, nuestra investigación se sitúa entre el análisis crítico del discurso y los estudios de glotopolítica histórica.

\section{APROXIMACIÓN TEÓRICA Y METODOLÓGICA}

En el contexto latinoamericano hacen falta estudios que analicen sistemáticamente la dominación y la erradicación de un determinado grupo social basadas particularmente en la manipulación del discurso lingüístico durante crisis políticas específicamente cargadas de violencia institucional o simbólica. Varios de los estudios disponibles tienden a analizar un corpus de documentos de archivo que articula el discurso hegemónico y las políticas socioeconómicas no más allá del marco de proyectos de consolidación

\footnotetext{
Este análisis se suma a nuestras investigaciones previas que han abarcado la representación lingüística, la historia intelectual, la racialización de la lengua, la construcción de fronteras lingüísticas y la propagación discursiva de la violencia mediante el despliegue de metáforas e ideologías lingüísticas, específicamente en el contexto del Caribe hispánico.
} 
nacional. Por ejemplo, en su evaluación final de la política lingüística durante el periodo de dictadura militar en Uruguay (1873-1984), Barrios y Pugliese (2004: 164) recalcan que "muchas de las decisiones en [la construcción de la identidad nacional] responden más a los valores simbólicos del lenguaje como fuerza unificadora o separatista dentro de una comunidad, que a necesidades reales de comunicación". Cameron (2008) y Jaffe (2008) han cuestionado varios aspectos problemáticos de esta aproximación, especialmente el carácter esencialista del discurso lingüístico utopista, la insistencia en que la condición socialmente vulnerable de un lenguaje se trata esencialmente de una mecánica construcción o desconstrucción de identidad. Según Jaffe (2008), esta forma de entender las cosas dificulta analíticamente la incorporación de lo político definido por los complejos debates lingüísticos que son siempre conducidos por actores sociales local y regionalmente situados con sus particulares intereses y agendas (sociales, políticas, económicas, etc.). En el contexto latinoamericano, el proyecto de estudios glotopolíticos liderado por Elvira Arnoux y José del Valle (2010) es un esfuerzo por superar las limitaciones de los paradigmas nacionalista y esencialista en Iberoamérica.

Precisamente, nuestro punto de partida es la aproximación contrahegemónica elaborada por estudiosos que sí analizan críticamente las relaciones de dominación política y la erradicación social basadas en la gestión del debate lingüístico en contextos específicos de violencia institucional o simbólica (Hutton 1999, Bormann, Cederman y Vogt 2017) y de evolutivos procesos de socialización o conflictos lingüísticos históricos (Heller y McElhinny 2017, González 2012, Meliá 1993). Heller (2008), en diálogo con Silverstein y Urban (1996) hace referencia a este tipo de inquietud epistemológica nuestra como el problema de "encontrar formas de describir la reinscripción o re-entextualización," o sea, las diferentes formas en que se actualizan y circulan de nuevo los viejos discursos sobre idioma, comunidad e identidad. Insistiendo en la necesidad de repensar la conexión entre identidad, poder y lenguaje. Para Heller (2008: 516) es más productivo enfocarnos en aspectos tales como recursos, trayectoria, valor e ideología del lenguaje para abordar la complejidad inherente y la condición borrosa de las categorías de análisis (entendidas como modos de organización social), no necesariamente como problemas a resolver, sino como lo que indispensablemente necesita ser investigado. Nuestro estudio se ubica precisamente dentro de esta rama crítica de la sociolingüística desconfiada. Investigamos genealógicamente los discursos históricos sobre la lengua en Guatemala para entender, describir y explicar la construcción de relaciones 
de poder ${ }^{4}$ mediante procesos de construcción de imaginarios sociales y la producción de textos y discursos que reproducen el dominio o jerarquías sociales. Abordamos el asunto de la delimitación de la economía del habla de ciertos grupos en relación con las exigencias de la economía política en el contexto de Guatemala. Las interrogantes que constantemente nos guían son: ¿quién produce qué discurso idiomático? ¿Cómo? ¿Cuándo? ¿Por qué? ¿Para qué y con qué efectos? Para ahondar en nuestro análisis, al final contrastaremos la experiencia y discursos de los filólogos y viajeros alemanes en Guatemala con algunos de sus contemporáneos y especialmente con la figura clave de Rodolfo Lenz quien ejemplificó otros modos de investigar y representar, digamos, menos ásperos.

\section{SELECCIÓN DE CORPUS Y CONTEXTOS SOCIOPOLÍTICOS}

Para organizar y ampliar nuestro corpus, necesitábamos algunas pistas sobre el trabajo de lingüistas y filólogos en distintos entornos de extrema violencia política, casos de matanzas y genocidio. Las historiadoras centroamericanas Patricia Alvarenga (2014) y Matilde González-Izás (2014) nos abrieron el camino. En Guatemala (1871-1950) encontramos textos y discursos clave de ciertos investigadores en varios campos, incluyendo etnología y lingüística, que influyeron decisivamente en la forma de ordenar e interpretar las capas, espacios y procesos sociales. En su genealogía crítica, González-Izás analiza, entre otros asuntos, los papeles que jugaron varios filólogos e intelectuales alemanes en concierto (algunas veces coherente, otras veces tenso) con las elites locales en el violento proyecto de modernización capitalista en Guatemala desde la independencia hasta mediados del siglo veinte. La autora esboza los diferentes modos en que los viajeros e intelectuales europeos (especialmente los alemanes) en Guatemala, "reinventaron los espacios sociales y ahondaron las formas de diferenciación de tipo racial ya existentes desde la Colonia" (González-Izás 2014: 169). El periodo de modernización capitalista que acompañó la construcción del Estado-nación en Guatemala

\footnotetext{
4 Con esta categoría nos referimos a las relaciones y prácticas sociales que contribuyen a los esquemas de superioridad/inferioridad (Quijano 2000).
} 
se destacó por la violenta acumulación de tierras cafetaleras y riquezas en manos de políticos, militares y empresarios que explotaron brutalmente a las multitudes indígenas. Curiosamente, durante este periodo el escenario intelectual guatemalteco fue definido por una alianza estratégica entre lingüistas y políticos, cuyo objetivo principal, como apunta French (2010) fue transformar a diversos grupos indígenas en cristianos guatemaltecos alfabetizados.

En este periodo, una gran diáspora alemana se asentó principalmente en Quetzaltenango, Alta Verapaz y Baja Verapaz. Sus miembros más activos contribuyeron a transformar la economía de la región. En torno a las tierras se tejió una alianza entre el Estado guatemalteco, las elites ladinas (mestizas) y militares y las firmas agroexportadoras estadounidenses y de Europa (principalmente alemanas ${ }^{5}$ ) y ocurrieron conflictos sangrientos. El legado de la diáspora alemana incluye aportes al mestizaje cultural guatemalteco más su participación en violaciones y genocidio patrocinado por el Estado (Gibbings 2016: 214). Las consecuencias de la modernización incluyeron choques entre los aparatos de represión del Estado, los inmigrantes europeos, las milicias criollas y los obreros indígenas que organizaron rebeliones locales. Nuestra prioridad investigativa son las circunstancias discursivas en torno a los conflictos entre finqueros alemanes, intermediarios ladinos y obreros indígenas en Las Tierras Altas, epicentro de la violencia finquera, el cual consistía en "un clima de abuso, arbitrariedad y disputa entre los patrones y administradores de las fincas, los intermediarios ladinos y los trabajadores indígenas" (Gonzáles-Izás 2014: 478). Los filólogos y etnógrafos que más se preocuparon por cuestiones lingüísticas fueron Otto Stoll (1849-1922), Karl Sapper (1866-1945), Franz Termer (1894-1968) y Leonhard Schultze-Jena (1872-1955). Como explica González-Izás la gran producción intelectual de este grupo contribuyó enormemente al conocimiento etnológico, lingüístico, geológico y botánico de regiones tales como Alta Verapaz en particular y de Guatemala en general. Nos enfocamos en el trabajo de estos estudiosos porque influyeron considerablemente en las formas de organizar e interpretar el territorio, la economía, la política, el Estado, la sociedad guatemalteca entre finales del siglo diecinueve y la primera mitad del veinte.

\footnotetext{
5 El cartógrafo, etnólogo y lingüista Karl Sapper, por ejemplo, terminó administrando una hacienda en un extenso territorio en el cual vivían 1,600 familias indígenas. (Su hermano, el empresario Richard Sapper también acumuló vastas tierras y riquezas). "Mi familia vino a cobrar a Guatemala... iy yo sigo cobrando!;" así dijo Johann Dietrich Nottebohm, nieto del empresario Arthur Nottebohm y actual dueño de Transcafé (citado en González-Izás 2014: 376), este último, uno de los descendientes directos de los inmigrantes alemanes.
} 
Nuestro corpus se compone de informes de investigación, etnografías, diccionarios lexicográficos, relatos de viaje, cartas y otros escritos misceláneos pero importantes. Accedemos a los textos mediante sus traducciones al castellano que forman parte del del archivo guatemalteco. Los ejemplos de discursos seleccionados nos permiten rastrear no solo las actividades de los protagonistas sino también las emergentes representaciones socioespaciales de Guatemala, las relaciones de poder y los conflictos vividos por los distintos grupos sociales ${ }^{6}$. Nuestra mirada como investigadores críticos se orienta en torno a la coyuntura de conflictividad, la cual emerge no solo en los paratextos producidos por los autores seleccionados, sino también en algunos lapsus e intersticios autocríticos de sus monografías.

\section{LA COMPULSIÓN HEGEMÓNICA EN LA FILOLOGÍA}

El viajero y pionero investigador en Centroamérica Otto Stoll (de nacionalidad suiza) abre uno de los primeros capítulos de su libro de viajes "Guatemala. Reisen und Schilderungen aus den Jahren 1878-1883" anotando como al presenciar el paisaje guatemalteco por primera vez el siguiente comentario de un estudioso francés (Morelet) le vino involuntariamente en mente: "L'aspect de Guatemala est triste: l'uniformité des constructions, l'absence de voitures, le silence et l'abandon des rues, pénètre l'étranger d'un sentiment d'ennui mortel, dès qu'il n'est plus stimulé par la curiosité" (citado en Stoll 1886: 16). Pese a esta sensación de antagonismo hacia el suelo guatemalteco, Stoll relata que fue la misma grandiosidad del paisaje que le ayudó a superar el carácter subjetivo de la ansiedad y decepción intelectual inicial. No obstante su esfuerzo por rescatar la objetividad, Stoll revela la inquietud y ansiedad existencial del observador ante el inicialmente incomprensible campo de estudio y cómo le urge hacer algo para cambiar el panorama desdeñable del campo que le ha tocado estudiar. En el prefacio de su texto fundacional Etnografía de la República de Guatemala (1938),

\footnotetext{
6 Sobre el discurso científico que caracteriza a estos textos, González-Izás señala que: "a pesar de que el lenguaje de las publicaciones producidas por estos académicos solía ser cauteloso y sobriamente descriptivo, tanto sus memorias como su narrativa de exploración y viaje expresan sus prejuicios, sus estereotipos y temores respecto al mundo social objeto de sus investigaciones y las relaciones conflictivas que establecieron con este" (2014: 178).
} 
Stoll nos ofrece otra reveladora descripción del contexto hegemónico en que emerge su mirada y que orienta su esfuerzo filológico:

Los lenguajes autóctonos de la América Central, pasan por una hispanización violenta e inevitablemente tienden a degenerar, lo cual es causado por el creciente trato que los indios tienen con la gente de la raza blanca del país, y sobre todo, con los mestizos que hablan solo el castellano. Por tal motivo, ya ninguno de los idiomas nativos se hablará en lo futuro, y no muy lejano, con absoluta pureza (XXXI).

Esta es una caracterización franca del régimen de hispanización a que fueron sometidas estas diversas culturas lingüísticas indígenas que enfatiza el rol que jugó la violencia en el paradigma de dominación hispana. Stoll pone de relieve la intercesión de lengua, violencia y raza que nos interesa examinar a lo largo de este estudio.

Karl Sapper, hermano del finquero Richard Sapper, es también reconocido como uno de los cartógrafos, naturalistas y filólogos procedentes de Alemania que más contribuyó al conocimiento botánico, geológico, etnológico y lingüístico de Guatemala. En Guatemala, perfeccionó su español y además aprendió el idioma q'eqchi'. Los mapas de este explorador y cartógrafo contribuyeron a trazar los límites de las zonas fronterizas y a la selección y apropiación de las mejores tierras para la explotación cafetalera por parte de su hermano y otros inversionistas. Trazó el primer mapa etnológico y lingüístico de la Alta Verapaz, dejando constancia de la complejidad sociocultural de los distintos grupos indígenas y subrayando sus variaciones culturales e idiomáticas. Su discípulo Termer (1946-1949) destaca los atributos empíricos del mapa lingüístico de Sapper:

En el cual se hallan separados del Chaneabal (el tojolabal de Sapper), dentro de nuestro territorio, el chuje y el jacalteca, ocupando aquel la parte septentrional y este la parte meridional de los Cuchumatanes. Desde entonces era costumbre dar el nombre de chuje a la lengua de los habitantes de los Cuchumatanes occidentales en general, limitando el jacalteco, que presenta ciertas afinidades con el chuje, a la aldea de Jacaltenango y sus inmediaciones (565).

En estos mapas de Sapper y en las discusiones posteriores de Termer, se puede detectar una inquietud singular por delimitar las fronteras lingüísticas y políticas: "en cuanto a los quichés, hay que hacer una marcada distinción entre la frontera lingüística y la frontera política, ya que estas en tiempos prehispánicos tampoco eran iguales" (Termer 1957: 4). Dicha preocupación va más allá de la ansiedad filológica causada por lo inadecuado que resultan las isoglosas para demarcaciones fronterizas. Estos filólogos percibían que 
entender las maneras en que se iba consolidando determinadas zonas de poder en la sociedad guatemalteca requería una comprensión de la correspondencia o divergencia entre el terreno, los cacicazgos y las zonas lingüísticas:

Cuanto menor era la unidad política indígena y más protegida como tal por la formación del terreno, más se cubrían las líneas fronterizas políticas con las fronteras lingüísticas. En situación distinta estaban los territorios centrales del altiplano. Allí las unidades políticas iban más allá de las fronteras originales de las razas y las lenguas (Termer 1957: 9-10).

Los matices lingüísticos anotados por Sapper en su mapa y posteriormente comentados por Termer son significantes no solo porque representan con mayor exactitud la complejidad sociolingüística de la zona sino también porque contribuyeron a la reclasificación étnica y lingüística que hizo, como reconoció el propio Termer, "desfilar ante nosotros los destinos de los indios hasta la actualidad, en que se ven incorporados como jornaleros al sistema de económico de la región costanera del Pacífico" (1946-1949: 566; el énfasis es nuestro). Los mapas y sus exegesis ayudaban a estos investigadores en la tarea de rastrear los lazos entre los conflictos interétnicos y la política del lenguaje. Por un lado, estos detalles eran fundamentales para establecer teóricamente los orígenes y límites del panmayanismo historiográfico, tarea asumida por discípulos guatemaltecos tales como el antropólogo y traductor de varios de los textos incluidos en nuestro corpus Antonio Goubaud (1964). Por otro lado, estos filólogos y etnógrafos sospechaban que este tipo de investigación contribuiría a una mayor comprensión de la ubicación y distribución de los grupos de poder y sus lealtades culturales. Para estos investigadores, cualquier indicio o anomalía lingüística sería crucial en esta empresa. Por lo tanto, Termer, el principal discípulo de Sapper, afirmó:

Sería interesante averiguar cómo fue originalmente el curso de la frontera de esta población [pipil] en la cuenca de Salamá [Guatemala]. El idioma quiché ha penetrado hacia dicha cuenca llegando hasta el pueblo de San Miguel Chicaj, mientras que el idioma pipil ya se ha extinguido. Más allá de San Miguel Chicaj, sigue un territorio lingüístico español. Si la mencionada penetración quiché en la cuenca de Salamá es una avanzada reciente, no lo sabemos y más deficiente es nuestro conocimiento sobre las poblaciones pipiles en el oriente de Guatemala, las que son de importancias esencial para establecer la relación con los pipiles de El Salvador (1957: 34).

Si algo tenían bien claro estos teóricos era que la expansión del poder iba acompañada de la influencia cultural, condicionada por la vitalidad de 
cierta lengua. En un determinado momento, el conocimiento etnolingüístico acumulado por Sapper y los estudiosos que lo siguieron facilitó la intervención del Estado y las élites locales y constituyó, como apunta González-Izás (2014: 198), "un instrumento para el ejercicio del poder” y "un medio eficaz para el control del espacio". Asimismo, la producción de estos mapas preparó el terreno para la segunda generación de investigadores alemanes que llegó a Guatemala en la primera mitad del siglo veinte.

La obra filológica del geógrafo, antropólogo y lingüista Leonhard Schultze Jena, proveniente de Alemania, hoy nos ayuda a comprender las culturas y la historia moderna de Guatemala. Schultze-Jena estudió las culturas del grupo indígena denominado k'iché (quiche) con especial atención a sus prácticas lingüísticas concretas. Un conjunto de nuestros datos discursivos proviene de su texto Leben, Glaube, und Sprache der Quiche von Guatemala (1933) traducido al español (en 1946 por el antropólogo Guatemalteco Antonio Goubaud Carrera, con ayuda de Herbert D. Sapper) bajo el título La vida y las creencias de los indígenas quiches de Guatemala. La historiadora centroamericana Patricia Alvarenga (2014) discute en términos muy positivos esta importante obra. En particular, Alvarenga sostiene que la concepción del trabajo etnográfico de Schultze-Jena junto con su especial interés por la cuestión lingüística hicieron que su enfoque fuera radicalmente distinto al de sus compatriotas, especialmente al de Termer ${ }^{7}$. De hecho, Schultze-Jena trabajó con rigor para demostrar coherentemente la diferenciación especifica que existía entre las ideologías indígenas y las de las culturas occidentales. Incluso, Alvarenga se refiere a la "sensibilidad etnográfica" de Schultze-Jena como novedosa (2014: 12). Sin embargo, nosotros estamos solo parcialmente de acuerdo con esta interpretación. En La vida y las creencias, de Schultze Jena, además de una ética científica integra, detectamos por momentos la mirada colonizadora, es decir, el deseo de apropiarse de un espacio epistemológico privilegiado (el conocimiento de los secretos de los k'iché) mediante el conocimiento de sus prácticas lingüísticas (su "tesoro lingüístico"). En la tercera página de su prólogo, Schultze-Jena escribió: "por medio de las oraciones fue como abrí la puerta para penetrar en el interior de esa cultura" (15). No cabe duda de que Schultze-Jena fue un excelente investigador, pero en ocasiones podemos observar que también fue motivado por la obsesión de clasificar racialmente a un grupo, en vez de entenderlo y explicarlo en su complejidad. Examinemos un ejemplo de su

\footnotetext{
(2008).

Para otros investigadores, Termer era el más vanguardista de los dos. Ver Perrot-Minnot
} 
proceder filológico: "Maritikum: me lo explicó el informante indio como el nombre de un antiguo soberano quiché" (82; énfasis nuestro). La mayoría de sus descripciones lingüísticas siguen este patrón, registro y tono formal y de máxima distancia profesional. En cambio, en los momentos en que se ocupa de reflexionar etnográficamente, no cabe duda de que se enriquece su obra y que le preocupaba humanamente el futuro de la población que estudiaba:

El pequeño comercio clandestino de antigüedades mexicanas, que se sustraen por tal motivo al estudio de la ciencia, no significa probablemente sino una mínima proporción de lo que todavía se conserva bajo tierra. Es mayor el peligro que amenaza a los rasgos espirituales de la antigua cultura indígena, a la tradición del pueblo y al vehículo que la trasmite, el idioma (Schultze-Jena 1954:14).

Hay cierta sensibilidad hacia la pérdida y el daño que representaban la hispanización cultural y lingüística de estos grupos indígenas. No obstante, en otras ocasiones, sus comentarios reflejan otros problemas de representación etnográfica, por ejemplo, al describirnos con más detalle su contacto con su objeto de estudio:

Directamente, de los labios del indígena recogí estas relaciones, tal y cual salían palabra por palabra de su boca. [...] hube de hacerle algunas preguntas; al parecer ingenuas, pero de contenido científico, tal y cual hace el médico cuando formula el diagnóstico de un enfermo, pues el indígena, al explicarse en un español limitado, con frecuencia sólo indica aproximadamente los conceptos que desea expresar, utilizando automáticamente para hablar el español, la construcción gramatical de su lengua materna (15).

De repente, los fenómenos de contacto lingüístico que inicialmente intuía Schultze-Jena como importantes pasan a un segundo plano. Apremia más resaltar la incapacidad de expresión del indígena en este contexto, su "incomunicabilidad racial," sin tomar en consideración las fuentes de poder y posición diferencial del grupo en esta sociedad. Schultze-Jena concibió ocasionalmente a su objeto de estudio, al indígena, como un enfermo y a sí mismo como un médico. Esta descripción paternalista es característica del legado autoritario de la cultura científica positivista en la cual el científico prescribe autocráticamente y antes de comprender el abanico de los síntomas; gesto el cual contribuye al avance de los intereses del científico y no, necesariamente, a los del informante.

Otro dato que nos llama la atención en el prólogo de Schultze-Jena es que no expresó ningún grado de agradecimiento a sus informantes indígenas. Sin embargo, sí agradece profusamente a las instituciones alemanas y 
guatemaltecas que lo financiaron y a uno de sus intermediarios ladinos. Schultze Jena describe al ladino Flavio Rodas en los siguientes términos:

Colaboró conmigo para hacer una revisión de los resultados obtenidos con los informantes, así como para aclarar el significado de algunos vocablos [...] El señor Rodas, nacido en Chichicastenango y contando en su ascendencia con elementos quichés, hubo de darme con toda cortesía su valiosa ayuda para vencer aquella desconfianza que siempre encuentra quien llega de extraño a un lugar como primer obstáculo en estos estudios. Por su cooperación le expreso al señor Rodas mi gratitud (1932:15-16; el énfasis es nuestro).

En este contexto lingüístico-etnográfico guatemalteco, era común reconocer y agradecer a los individuos intermediarios que facilitaban la labor de los investigadores, pero no a los informantes proveedores de datos, gesto que les resta agencialidad a los informantes.

En el comentario previo hay una la alusión importante a un paradigma discursivo en particular, el de "la desconfianza indígena." ¿Qué está en juego aquí? Se trata de uno de los tópicos característicos del discurso etnólogo occidental (pero específicamente europeo) en el contexto guatemalteco: "la natural indolencia" del indio y "su gran desconfianza". Estas frases, que se derivan del discurso de los cronistas y etnógrafos españoles durante la colonización fueron reproducidas por Stoll ([1884] 1938: XXXII), se repiten en los textos de Termer y de Schultze Jena. Abordando el tema de la desconfianza, Schultze-Jena escribió: "el indígena se expresa cuando siente confianza. No gusta de cosas abstractas, prefiriendo mostrar la evidencia que proviene de su propia experiencia [...] Resuelve dramáticamente la acción por medio del diálogo y la facilidad con que le fluye la palabra siempre que usa un método de expresarse es sorprendente" (1954: 15). Para Alvarenga, este tipo de enunciaciones no es patriarcal ni autoritaria, "más bien trasmite la imagen de una persona fascinada ante la diferencia, se empeña más que en posesionarse de su conocimiento, en ser partícipe de este" (2014: 13). En cambio, González-Izás sugiere que estas repetidas quejas sobre "la indolencia y desconfianza del indio" revelan la incapacidad de los científicos para reconocer la agencialidad indígena y también permiten observar la preocupación de estos filólogos por ejercer cierta coacción sobre ellos (2014: 185). En efecto, no detectamos compulsión hegemónica en el caso de esta última reflexión de Schultze Jena, pero, en conjunto, sí observamos esta enunciación como una expresión discursiva de la conflictividad y tensión vivida entre los científicos y los grupos indígenas que estos estudiaban. Los estudiosos anhelaban estudiar a estas poblaciones en su "estado natural," es decir concentrándose en los elementos culturales precolombinos que aún 
preservaban tales como sus creencias y sus hablas. Sin embargo, el contacto con los mismos científicos que los estudiaban para incorporarlos al nuevo régimen social, según las directrices del nuevo orden político-económico, alteró sus conductas.

No cabe duda de que estudiosos tales como Schultze-Jena llevaron a cabo gran parte de sus actividades de investigación comprometidos con el objetivo de desarrollar el conocimiento necesario para entender a estos grupos sociales y avanzar en sus respectivas disciplinas. Si bien ejemplificaron un gran compromiso profesional, también es cierto que sus obras reflejan las corrientes políticas que los envolvían y empujaban hacia ciertas conclusiones y aplicaciones de los resultados de sus investigaciones. Sus obras son el resultado de una disciplina intelectual admirable pero también de un ambiente político regido por varias fuerzas en pugna por el control de diversos grupos sociales y la posesión de las tierras más valiosas. Precisamente, cuando Termer discute algunos aspectos del fenómeno de la violencia, nos percatamos de los choques específicos entre ideas y grupos que buscan acomodarse, representarse o resistir dentro de un determinado espacio social:

Multitud de ideas vagas y confusas que se viene formando la gente acerca de los ritos que los "evangelistas" practican a puertas cerradas encierran los gérmenes de repentinas violencias cometidas por la población que sigue profesando la fe antigua, violencias, que según lo atestiguan los ejemplos de antaño, pueden exteriorizarse en forma de terribles atrocidades perpetradas contra blancos y ladinos (Termer 1946-1949: 567).

Esta alusión a "los gérmenes de repentinas violencias" es significativa. Se entendía que existía una violencia en potencia encarnada por la frustración socioeconómica de los diversos grupos indígenas. Entender las lenguas y las creencias de estos grupos era clave para prevenir a los demás grupos de interés y evitar rebeliones. Termer se había percatado de que había que tener en cuenta los fenómenos de la violencia simbólica que preceden o siguen a la violencia material. Y había una conciencia de los orígenes, objetos y métodos de los distintos tipos de violencia.

A ratos desprendiéndose algo de la perspectiva colonial, como señala González-Izás, Stoll escribió una serie de críticas sobre las condiciones de opresión y violencia que vivían los trabajadores indígenas en las fincas cafetaleras de los hacendados alemanes: "el finquero valoraba a un peón menos que a un esclavo" (Reisen und Schilderungen aus den Jahren 18781883: 88). En esta instancia, Stoll expresó una visión crítica del panorama sociopolítico que se vivía en los campos que eran su objeto de estudio. Sin embargo, pese a su visión independiente que demuestra parcialmente en 
su obra, se empeñó en establecer su autoridad científica sobre su objeto de estudio, los indígenas:

En el libro que escribiré sobre mi viaje a Guatemala, tendré ocasión de relatar algunas de las dificultades que se presentan al que se propone "investigar científicamente al indio," causadas tanto por su "natural indolencia," como por la gran desconfianza que tiene a todo lo que es nuevo o extraño para él (1883/1953: XLIX).

Los tanteos críticos de Stoll nos ponen en relieve un aspecto de la coyuntura de la conflictividad que hemos venido rastreando mediante la descripción lingüística y reflexión etnográfica en Guatemala: el estudio de los grupos indígenas implicaba varios métodos concretos y simbólicos de dominación.

Stoll y Termer, cada uno a su modo, dieron cuenta de la profunda tensión que había entre los exploradores extranjeros y los indígenas y que también existía entre los estudiosos mismos, debido a que trabajaban bajo un alto grado de competencia (enmascarada con el método científico). En este sentido es preciso observar el contraste que traza Termer entre los métodos de investigación de Schultze-Jena y el antropólogo estadounidense Oliver La Farge. Según Termer, Schultze-Jena:

Deduce la ideología de los indígenas de sus oraciones y sermones propios, así como de sus diálogos pertenecientes a las ceremonias y ritos interpretando etnológicamente las investigaciones lingüísticas exactas, mientras que Lafarge interroga a sus informadores de confianza indios, y estableciendo contacto íntimo y diario con la vida de los indígenas, va estudiando y observando el mecanismo de su estructura familiar y el significado del rito y de las ceremonias del culto (1946-1949: 568).

$\mathrm{Al}$ contrastar las diferentes tendencias metodológicas y explorar las zonas de consenso entre los distintos filólogos, Termer también revela el grado de competitividad que rodeaba aquel entorno profesional.

Los investigadores en Guatemala cuyas intervenciones hemos analizado representan (como reconoce el propio Termer), la cara menos agradable de la tradición académica alemana, estudiosos que combinaron sus actividades y ambiciones capitalistas con sus métodos científicos. Las interesantes observaciones y críticas de Termer merecerán un estudio aparte, pero debemos aclarar que emergen como parte de su inquietud por el desplazamiento de los investigadores alemanes ante la emergente hegemonía estadounidense en Centro América. No obstante, la zona de colaboración que se creó entre la gran mayoría de estos científicos, los empresarios y políticos giraba en torno a un objetivo fundamental: "Centroamérica debía ser trasformada en un escenario de trabajo y eficiencia" (González-Izás 
2014: 225). Los estudiosos cuyos textos y discurso hemos analizados hasta el momento, en combinación con los demás intelectuales internacionales y locales, se sumaron a este proceso, dedicándose a escudriñar la diversidad étnica y lingüística guatemalteca, influidos por la percepción fundamental de que el lenguaje ejerce poder sobre la realidad.

\section{RODOLFO LENZ O LA BUENA VOLUNTAD FILOLÓGICA}

El contraste que hace Alvarenga (2014) entre las figuras y las obras de Schultze-Jena y Termer nos aclara algunas dudas en cuanto a la cuestión de dónde se ubica cada cual en torno a la coyuntura de la conflictividad sociocultural en Guatemala. Pero para mejor comprender las conductas y el impacto hegemónico de los investigadores alemanes en Guatemala, intentamos considerar qué sucede (en contextos parecidos) cuando la mirada del investigador hacia su objeto de estudio es otra; menos colonizadora, más amable, más utópica. Para ofrecer el mayor contraste, decidimos regresar a la obra y figura de Rodolfo (Rudolph) Lenz (1863-1938), científico de gran sensatez, de gran rigor en su trabajo y al parecer de una personalidad amable y amorosa. Leer, por ejemplo, los prólogos de las obras de Lenz es como leer cartas a un buen amigo o a un ser muy respetado y querido. Lenz nació y se formó en Alemania, pero vivió y trabajó en Chile por casi cinco décadas. Muchas de sus obras fundamentales fueron publicadas en español en Latinoamérica.

Al comparar la obra de Lenz, su aproximación, su metodología y sus conclusiones con la obra de sus contemporáneos alemanes en Guatemala, observamos unas grandes diferencias. En el prólogo de su libro "El papiamento" (1928), Lenz repetidas veces se dedica a reflexionar sobre el primer momento de contacto epistemológico, ubicar etnográficamente al sujeto parlante y al productor de textos, incluyendo información sobre sus respectivos contextos. Por ejemplo, así describió Lenz a su informante creole-parlante:

Al día siguiente tuve la primera conversación con el héroe de estas pájinas, el segundo cocinero del buque, el negro Natividad Silie (pronunciado Sili). Hablé con él alternativamente en castellano i en inglés, i me contestó en las dos lenguas con toda facilidad (1928: 7). 
Si bien es cierto que Lenz nos ofrece una introducción un poco influida por una imaginación dramática-literaria ("el héroe de estas páginas"), esta manera de abrir un espacio epistemológico delata cierta conciencia y sensibilidad científica singular. Esta particular caracterización contrasta con la anonimidad problemática del sujeto-objeto que construyen y la distancia que toman los filólogos con tendencias positivistas tales como Sapper y Schultze-Jena. En este punto, Lenz supera ese hábito de reducción e integra la lección de Malinowski que, como apuntan Clifford (1988) y Blommaert (2010), consistía en que el investigador tomara conciencia de su propia participación activa.

Aunque emerja como el héroe de nuestros párrafos en esta monografía, no se trata de idolatrar a Lenz. Bien podríamos también considerar sus fallos, ambivalencia o su frágil defensa del creole como lengua popular. Sin embargo, al detenernos sobre los minuciosos detalles de su proceder, nos damos cuenta de que estamos ante un investigador especial, un investigador con un gran interés por las condiciones de vida y su diversidad. Así leemos al principio en su prólogo: "le pedí primero datos sobre su vida, enseguida cantos i cuentos populares que recordara [...]" (Lenz 1928: 8). En el párrafo siguiente Lenz pone en claro su punto de partida, punto de ignorancia que con gran entusiasmo y responsabilidad intenta corregir:

No había en mi vida tratado con un negro; [...] son muy raros en Chile: más escasos que en cualquier ciudad europea. No puedo negar que desde luego mi interés lingüístico fue acompañado de cierto interés psicológico por el coloured gentleman. Los que lean las pájinas siguientes me comprenderán (1928: 8).

En algún determinado momento, en nuestros respectivos campos de trabajo, hemos sido partícipes, cómplices en o testigos de la estratégica o hipócrita barrida de la ignorancia bajo la alfombra. Por eso es tan refrescante observar el reconocimiento franco de la ignorancia o el interés por lo más desconocido como el punto de partida de un investigador proveniente de una determinada cultura científica. La tendencia entre los positivistas es asociar automáticamente actitudes de franqueza intelectual tales como las de Lenz con falta de rigor o vulnerabilidad.

El tono íntimo y autoconsciente en la explicación preliminar de Lenz está muy lejos de la desmesurada fuerza retórica y la arrogancia intelectual positivista. Varios párrafos más adelante, Lenz recalca:

De consiguiente debía ser de interés lingüístico particular obtener documentos escritos por el término medio del pueblo, que representaran el "lenguaje natural." Este es, en mi entender, el mérito principal de los 
documentos que debo a la buena voluntad de mi negro Natividad Silie (1928: 10).

En un próximo estudio, nos detendremos a observar los detalles contrastivos de la construcción discursiva de ambos paradigmas: el de "la natural indolencia del indio" y el de "la buena voluntad de mí negro." Igual, estas expresiones de gratitud no eximen totalmente a Lenz del racismo. Como observan Pfänder y Ennis (2013), a Lenz le tocó albergar ciertos prejuicios raciales (y, agregamos, típicos de una persona que es producto de su época). Sin embargo, es necesario aclarar que, dentro del contexto filológicoetnológico latinoamericano de su época, Lenz llegó más lejos que cualquier otro en su aproximación crítica al punto donde convergen fenómenos lingüísticos, raciales e históricos. Recordemos una de sus intervenciones sobre el contacto lingüístico Chile:

No hace un siglo todavía que los chilenos se gloriaban de ser descendientes de la más valerosa raza americana por la mitad de su sangre. En mi libro verán sin falsa vergüenza hasta qué grado también le deben la lengua, su pensamiento. Este enorme número de palabras araucanas i quechuas incorporadas en la lengua castellana son como las cicatrices de la lucha jigantesca en que el español de Chile venció al indio de Chile, i lo obligó a aprender un idioma europeo i a formar con él una nacionalidad nueva i firme, la más sólida i homojénea que se enjendró en suelo americano pisado por español (Lenz 1910: 41).

Si bien es cierto que la tesis araucanista fue luego abandonada por el mismo Lenz, consideramos admirable su gestión por rescatar el protagonismo, la agencialidad, de estos distintos grupos colonizados. Como sugieren Pfänder y Ennis (2013: 121), las descripciones y reflexiones de Lenz revelan una conciencia filológica muy particular sobre la violencia en la historia. Al contrario de los filólogos hispanistas relevantes de su época, Lenz explica con sensibilidad la historia lingüística de Chile como el resultado de contactos problemáticos y altamente conflictivos:

Chile se distingue de la mayor parte de los países hispano-americanos en que su habitantes desde el último inquilino hasta el hacendado más pudiente constituyen una nación uniforme de lengua castellana que se ha formado por la mezcla de los conquistadores e inmigrantes españoles con las más orgullosa i valiente de las tribus indíjenas de América, los araucanos Estos mismos, como tantos otros pueblos de baja cultura, se llaman simplemente "la gente del país" mapuche, i se conservan puros sólo en algunas provincias del sur, en las cuales la cultura va haciendo rápidos progresos, internándose en las selvas vírgenes con los ferrocarriles 
que ponen en comunicación las ciudades i aldeas, nacidas de antiguos fuertes españoles i al rededor de las colonias agrícolas. Alla siguen viviendo los indios, o más bien, vegetando i acabándose, esterminados por el alcohol i la rapiña del blanco civilizado que les quita sus tierras (1894/1919: 517-518; el énfasis es nuestro).

Estamos muy lejos del cuadro de absorción puramente cultural u osmosis armónica descrito por hispanistas tales como Amado Alonso, Américo Castro y Ramón Menéndez Pidal. Lenz destaca el choque entre conquistadores europeos y defensores indígenas y los mecanismos de explotación socioeconómica mediante las cuales el conquistador mantiene su dominación y control. Las obras filólogas de Lenz parten de e intentan regresar a "ese punto de inflexión, ese plantear preguntas a contrapelo del imperio de la lengua" como afirma Bernaschina Schurmann (2013: 131).

\section{CONCLUSIONES}

Hemos intentado yuxtaponer la filología etnográficamente crítica de Lenz con la práctica filológica institucionalizada. Lenz deconstruye la autoridad hegemónica al subvertir la postura privilegiada del filólogo sobre sus informantes. Junto a Knauer (1984), Pfänder y Ennis (2013), y Bernaschina Schurmann (2016), consideramos a Lenz como pionero en el desarrollo de la filología crítica en América Latina. En cambio, al considerar las descripciones y la auto-representación de los filólogos alemanes en Guatemala, observamos, igual que González-Izás (2014: 184), que la tendencia es a enfocar el brillante significado de sus obras y lo completo, nítidos y elegantes que parecen sus conocimientos. Leyendo a contrapelo, uno detecta en la obra de los Sapper, por ejemplo, una convicción de que el saber debe rentabilizarse, de un modo u otro, y la acumulación de conocimientos debe conducir naturalmente a la acumulación ${ }^{8}$ de riquezas materiales o simbólicas y a la densidad hegemónica.

Por lo tanto, nos cautivan figuras como Lenz porque su discurso y prácticas filológicas tienen efectos contrarios a la compulsión hegemónica que solemos

8 González-Izás (2014: 200) proporciona varios detalles sobre la evolución de Karl Sapper de científico a hacendado. 
encontrar en la filología tradicional y la lingüística formal. En conjunto y en contraste con los demás, sus descripciones, conclusiones y gestos constituyen un rechazo al impulso hegemónico y sus intervenciones representan un riesgo y una apuesta particular por lo que aporta el saber filológico al experimento de la democracia. ¿En qué consisten exactamente ese riesgo y esa apuesta? Consisten en adoptar la actitud de que lo primordial es comprender "las exigencias de la necesidad de la vida" (para volver a citar a Lenz). Sin duda, la simplificación y la reducción de la complejidad, el método científico, han posibilitado grandes descubrimientos y avances de gran beneficio para la humanidad, pero también conforman métodos de homogeneización, control y dominación de lo indefinido, lo oscuro, lo desordenado y lo indomable. Y si bien es cierto que filólogos como Lenz buscaban mejorar e institucionalizar "un conjunto de técnicas y procedimientos científicos," la filología crítica también implicaba cultivar cierta sensibilidad hacia uno mismo y hacia los demás. Así es como imaginamos el temperamento y el proceder de un Lenz, motivado por el deseo vital de contribuir al progreso del oficio, pero también al mejoramiento propio y la felicidad personal y del otro a través del saber filológico crítico. Esta confianza estrecha e íntima ilustrada por Lenz es parte del procedimiento que destacara Hymes ("the conditions of trust and confidence") como requisito fundamental de la etnografía (1980, 99). A nuestro entender, esta actitud utópica está muy lejos de la ley de competitividad en que trabajaron particularmente los Sapper, Termer y Schultze Jena, entre los filólogos aquí examinados, probablemente los más interesados en describir (y a veces disfrazar), a través del lenguaje, el funcionamiento del poder.

\section{REFERENCIAS BIBLIOGRÁFICAS}

Alvarenga, Patricia. 2014. El otro en la mirada etnográfica. Guatemala (1920-1950). Cuadernos de Antropología 24 (2): 3-24.

Arnoux, Elvira Narvaja y José del Valle. 2010. Ideologías lingüísticas y el español en contexto histórico. Spanish in Context 7 (1): 1-24.

Barrios, Graciela y Leticia Pugliese. 2004. Política lingüística y dictadura militar: las campañas de defensa de la lengua. En Aldo Marchesi et al. (eds.). El presente de la dictadura: estudios y reflexiones a 30 años del golpe de estado en Uruguay. Montevideo: Ediciones Trilce, pp. 156-167.

Bernaschina Shürmann, Vicente. 2013. Rodolfo Lenz, 150 años en disputa con el imperio de la lengua. Universum 28 (2): 117-137.

2016. Rodolfo Lenz: hacia una filología crítica americana. En Sergio Ugalde Quintana y Ottmar Ette (eds.). Políticas y estrategias de la crítica: ideologías, historia 
y actores de los estudios literarios. Berlín: Publicaciones del Instituto Ibero-Americano, pp. 121-137.

Blommaert, JAN Y Dong Jie. 2010. Ethnographic fieldwork: a beginner's guide. Bristol/Buffalo/ Toronto: Multilingual Matters.

Bormann, Nils-Christian, Lars-Erik Cederman y Manuel Vogt. 2017. Language, religion, and ethnic civil war. Journal of Conflict Resolution 16 (4): 744-771.

CAmeron, DeBorah. 2008. Language endangerment and verbal hygiene: history, morality and politics". En Alexandre Duchêne y Monica Heller (eds.). Discourses of endangerment: ideology and interest in the defence of languages. Nueva York/Londres: Continuum International Publishing, pp. 268-285.

CLIFFORD, JAMES. 1988. The predicament of culture: twentieth-century ethnography, literature, and art. Cambridge, Massachusetts: Harvard University Press.

FrenCH. BRIGITTINE M. 2010. Maya ethnolinguistic identity: violence, cultural rights, and modernity in Highland Guatemala. Arizona: University of Arizona Press.

GibBings, JuLie. 2016. Mestizaje in the age of fascism: German and Q'echi' Maya interracial unions in Alta Verapaz, Guatemala. German History 34 (2): 214-236.

GonzÁlez-IzÁs, Matılde. 2014. Modernización capitalista, racismo y violencia: Guatemala (1750-1930). Ciudad de México: El Colegio de México.

GonzÁlez, José Alberto. 2012. Los conflictos del lenguaje: el lenguaje una caja de Pandora. Rastros Rostros 14 (27): 75-82.

Goubaud Carrera, Antonio. 1964. Indigenismo en Guatemala. Guatemala: Ministerio de Educación Pública.

Heller, Monica. 2008. Language and the nation-sate: challenges to sociolinguistic theory and practice. Journal of Sociolinguistics 12 (4): 504-524.

y BobBie McElhinny. 2017. Language, capitalism, colonialism: toward a critical history. Toronto: University of Toronto Press.

Hutton, Christopher. 1999. Linguistics and the Third Reich: mother-tongue fascism, race and the science of language. Londres/Nueva York: Routledge.

Hymes, Dell. 1980. Language in education: ethnolinguistics essay. Washington D.C.: Center for Applied Linguistics.

Jaffe, Alexandra. 2008. Discourse of endangerment: contexts and consequences of essentializing discourses. En Alexandre Duchêne y Monica Heller (eds.). Discourses of endangerment: ideology and interest in the defence of languages. Nueva York/Londres: Continuum International Publishing, pp. 57-75.

KNAUER, GABRIELE. 1984. Filólogos alemanes en América Latina: Rodolfo Lenz y el europeísmo cultural en el discurso científico de la lingüística iberoamericana. En Hans-Otto Dill / Gabriele Knauer (eds.). Diálogo y conflicto cultural: estudios comparativos de procesos transculturales entre Europa y América. Madrid: Vervuert, pp. 139-152.

Lenz, RudolPh. 1894/1919. Sobre la poesía popular impresa de Santiago de Chile: contribución al folklore chileno. Santiago: Separata de los Anales de la Universidad de Chile. Memorias Científicas y Literarias Mayo-Junio 1894.

1910. Los elementos indios del castellano de Chile. Estudio lingüístico y etnolójico. Primera parte. Diccionario derivado de lenguas indíjenas americanas. Santiago: Imprenta Cervantes.

1928. El papiamento. La lengua criolla de Curazao. La gramática más sencilla. Santiago: Anales de la Universidad de Chile.

Melí, BARTOMeu. 1993. El guaraní conquistado y reducido: ensayos de etnohistoria. Asunción, Paraguay: Biblioteca Paraguaya de Antropología. 
Perrot-Minnot, Sébastien. 2008. Los recorridos del doctor Termer. El Diario de Hoy (El Salvador, 6 de julio de 2008. https://sebastienperrotminnot.wordpress.com/2015/10/11/ los-recorridos-del-doctor-termer-el-diario-de-hoy-el-salvador-06072008/.

Pfänder, Stephan y Juan Antonio Ennis. 2013. Lo criollo en cuestión: filología e historia. Buenos Aires: Ediciones Katatay.

Quijano, Aníbal. 2000. Colonialidad del poder, eurocentrismo y América Latina. Buenos Aires: CLACSO.

Schultze-Jena, LeOnhard. 1933/1954. La vida y las creencias de los indigenas quichés de Guatemala. Guatemala: Ministerio de Educación Pública.

1933. Leben, Glaube, und Sprache der Quiche von Guatemala. Jena: Von Gustav Fischer.

Silverstein, Michael y Greg Urban. 1996. Natural histories of discourse. Chicago: University of Chicago Press.

Stoll, Отто. 1884/1938. Etnografía de Guatemala. Guatemala: Ministerio de Educación Pública.

1886. Guatemala. Reisen und Schilderungen aus den Jahren 1878-1883 [Guatemala, viajes y descripciones durante los años 1878-1883]. Leipzig: F. A. Brockhaus.

1889. Die Ethnologie der indianerstamme von Guatemala. Leiden: Verlag von P.W.M. Trap.

Termer, Franz. 1946-1949. Nuevas investigaciones sobre los mayas altenses del Noroeste de Guatemala. Antropos 40 (44): 561-576.

1957. Etnología y etnografia de Guatemala. Guatemala: Editorial del Ministerio de Educación Pública.

1930. Zur Ethnologie und Ethnographie des nördlichen. Mittelamerika. IberoAmerikanisches Archiv 4 (3): 301-492. 